\title{
Gostar de ler: mapeamento de leitura junto a alunos da $4^{\mathrm{a}}$ série
}

\section{Enjoy reading: mapping reading with students from fourth grade}

\author{
Cristina Nalon de Araujo ${ }^{1}$
}

\begin{abstract}
Resumo
Nesta pesquisa, verificou-se o modo como professores e alunos da $4^{\text {a }}$ série do ensino fundamental de oito anos de três escolas públicas de uma cidade de médio porte no norte do Estado do Paraná compreendem o significado de leitura. Essa verificação foi efetuada por meio de observação em sala de aula e da aplicação de questionário. Reconhece-se que, desde sempre, a leitura teve grande relevância na sociedade e, nesse começo do século XXI, ela tem se mostrado ainda mais forte, devido ao aumento das publicações impressas e das demais formas de sua manifestação, como a imagem, divulgada amplamente nos meios sociais. Ainda que no Brasil o nível de desempenho da leitura dos estudantes do Ensino Fundamental não se mostre satisfatório, os resultados obtidos nesta pesquisa, junto aos alunos, revelam o fortalecimento dos laços que eles estabelecem com a leitura. No entanto, o ato prazeroso de ler nem sempre surge espontaneamente ou, ainda, o leitor em potencial pode ser sufocado por diversos fatores influenciadores, daí a necessidade da intervenção de instituições próximas às crianças, a fim de que se tornem leitores, e mais que isso, leitores críticos, transformadores da sociedade. Neste sentido, apresentam-se neste artigo contribuições com vistas ao ensino da leitura na escola.
\end{abstract}

Palavras-chave: Educação escolar. Leitura. Prazer de ler.

\begin{abstract}
In this research we analyzed the way teachers and students from the fourth grade of elementary school, in eight years, at three public schools in a midsize city in the north of Paraná State understand the meaning of reading. The study was conducted through observation in the classroom and by applying a questionnaire. It is recognized that the reading had always been very important in society, and at the beginning of this century it has presented itself even stronger due to the increase in printed publications and other forms of its manifestation, as the image, published widely in social media. Although in Brazil the level of reading performance of elementary school students does not seem satisfactory, the results obtained in this research with students show the strengthening of ties they have with reading. Nevertheless, the pleasant act of reading does not always arise spontaneously, and also the potential reader can be suppressed by several influencing factors, then there is the need for intervention by institutions close to children, so they become readers, and more than that, critical readers, society transformers. In this sense, we present in this article contributions to the teaching of reading in school. Keywords: School education. Reading. Pleasure in reading.
\end{abstract}

\footnotetext{
${ }^{1}$ Aluna do curso de Pedagogia da Universidade Estadual de Londrina. Email: crisflor_18@hotmail.com.
} 


\section{Introdução}

A questão da leitura, presente no cotidiano das pessoas e, em especial, no dia-a-dia das crianças, revela-se como algo indispensável em todo o desenvolvimento de nossas vidas, pois o ato de ler extrapola a palavra escrita e, como Freire (1999) já salientou, tem sentido na compreensão de mundo que é constituída pelo individuo por meio da prática.

Essa prática também traz consigo a experiência do prazer, pois, além dos benefícios da leitura como maior poder de compreensão, vocabulário mais amplo, criticidade na leitura da palavra e de mundo, a vivência do ato de ler proporciona bem estar, satisfação e gosto, quando é feita com assiduidade, e passa a ser um exercício desprovido de obrigação. Podemos dizer que esse é um sinal de contentamento encontrado no ato de ler.

O prazer que encontramos na leitura dificilmente terá uma definição específica, sendo ele subjetivo e pessoal. No entanto, pode-se ao menos arriacar a apresentar de algumas pistas, possíveis indicadores dos motivos que levam ao ato de ler. Entre eles: a interação que o leitor faz com o texto e com o autor, a relação da palavra escrita com a realidade do leitor, a desobrigação pela prática da leitura, a escolha do gênero textual correspondente ao interesse de quem está lendo e a curiosidade, entre outros. Roland Barthes nos ajuda a entender um pouco mais sobre o prazer em ler:

[...] o lugar do prazer numa teoria do texto não é certo. Simplesmente, chega um dia em que se sente alguma urgência em desparafusar um pouco a teoria, em deslocar o discurso, o idioleto que se repete, toma consistência, em lhe dar a sacudida de uma questão. O prazer é essa questão (BARTHES, 1973, p. 83-84).

A busca independente pela leitura, seja ela qual for - livros, revistas, jornais, publicidade nas ruas, textos virtuais, música, etc - é um passo para que alguém se torne leitor assíduo, ou seja, alguém que se viu atraído pela leitura, pois o despertar da vontade de ler já mostra um potencial de leitor comprometido com essa prática, e isso é almejado para a vida de todos os cidadãos.

Há muito tempo o Brasil enfrenta sérios desafios quanto à leitura desde muito tempo e essa questão tem impactos ainda hoje na população, particularmente, nas classes mais desfavorecidas da sociedade. No entanto, autores, pesquisadores e docentes que acreditam em mudanças e fazem acontecer na prática a convocação para a leitura, têm dado suas contribuições para que ela deixe de ser mais um elemento de privilégio e se transforme em direito e acesso de todos.

Cabe lembrar que a motivação para que a leitura se realize na vida de todas as pessoas passa pela compreensão de seu significado. Uma vez experimentado o gosto pela leitura e as conseqüências desse ato, torna-se cada vez mais difícil de se esquivar dessa vontade que traz além da satisfação, a libertação das amarras de uma sociedade que exclui, limita e aliena as pessoas.

Tendo em vista esses aspectos positivos da leitura, esta pesquisa teve como objetivo compreender o significado e a importância do ato de ler em meio aos alunos e professores da $4^{\mathrm{a}}$ série do ensino fundamental. Os procedimentos, ao longo do estudo, contemplaram a revisão literária de obras que envolvem a leitura, especialmente na escola e na biblioteca, e a coleta de dados obtida por meio da observação e a aplicação de questionários. A análise e interpretação dos dados tiveram base em uma abordagem qualitativa, e não desconsideraram o lado quantitativo.

A seguir, será caracterizada a pesquisa e farse-á uma breve descrição da leitura na sociedade brasileira, para que sejam explicitados os resultados obtidos na coleta de dados realizada no último bimestre de 2009, em três escolas públicas em uma cidade de médio porte no norte do Estado do Paraná.

A pesquisa teve como público alunos que estão na $4^{\text {a }}$ série. Para termos de esclarecimento legal, essa série corresponde ao $5^{\circ}$ ano dos anos iniciais do Ensino Fundamental de nove anos, isso porque 
houve uma mudança no art. 32 da Lei 9394 de 1996 (LDB). A lei 11.274 de 2006 altera a redação desse artigo (32), dispondo sobre a duração de 9 (nove) anos para o ensino fundamental, com matrícula obrigatória a partir dos 6 (seis) anos de idade e estabelece prazo de implantação, pelos sistemas, até 2010. Como as escolas junto às quais a pesquisa foi desenvolvida não haviam ainda implantado essa mudança no período em que coletamos dados, consideramos $4^{\mathrm{a}}$ série e não $5^{\circ}$ ano o grupo com o qual trabalhamos.

\section{Caracterização da Pesquisa}

No período de coleta de dados, participaram da pesquisa três escolas públicas, que oferecem ensino fundamental, escolhidas em uma cidade de médio porte no norte do Estado do Paraná. O trabalho foi realizado após os devidos procedimentos para a entrada nas escolas, pois, além do questionário aplicado aos alunos e professores, foi feita uma semana de observação em cada escola.

O questionário foi realizado com alunos da $4^{\mathrm{a}}$ série do ensino fundamental de oito anos, visandose a compreender a leitura e seu significado para esses alunos. A $4^{\mathrm{a}}$ série foi escolhida como públicoalvo pelo fato dos alunos estarem na última série de uma etapa escolar e, espera-se, preparados para um novo momento na escola.

As escolas e participantes da pesquisa não terão seus nomes identificados, e as escolas serão representadas pelas letras $\mathrm{A}, \mathrm{B}$ e $\mathrm{C}$.

O referido questionário foi respondido por 79 discentes entre 9 e 12 anos, sendo 30 deles da escola A, 23 da escola B e 26 da C. Dentre esses alunos, $54,43 \%$ são do sexo masculino, e na escola A eles representam 66,66\%; na escola $B$, são 47,82\%; e na C, $46,15 \%$. Obteve-se um total de $100 \%$ de questionários respondidos nas três escolas.

A primeira parte do questionário dos discentes (ver apêndice A) foi elaborada com o intuito de entender-se a leitura em geral, com perguntas sobre o gosto, o interesse, a importância e o que é leitura. $\mathrm{Na}$ segunda parte, as questões se referiam à leitura e à biblioteca.

Para os professores desses alunos também foi organizado um questionário (ver apêndice B) para perceber-se o ensino da leitura na escola e o olhar do docente em relação aos seus alunos e à leitura.

Entre professores e auxiliares, ao todo, seis colaboraram com o preenchimento do questionário nessas três escolas. $100 \%$ são mulheres e a maioria tem formação em pedagogia e especialização em alguma área da educação.

\section{Considerações sobre a Leitura}

“[...] eu diria que ler é, [...] possuir elementos de combate à alienação e ignorância" (SILVA, 1986, p. 49). Assim nos diz Ezequiel Theodoro da Silva, que explica a leitura como um meio para a compreensão crítica da realidade do leitor, uma leitura que deve ser ser emancipadora e auxiliar o homem a atingir plenamente sua dignidade.

Essas são algumas características que revestem a leitura, pois ela vai além da mera decodificação das palavras e transpassa o puro decifrar, completandose na compreensão da palavra escrita do autor e na prática cotidiana de sua significação.

Um alfabetizado que se torna leitor é alguém que não viu possibilidade de permanecer no primeiro estágio da leitura, e se viu obrigado, por vontade própria, a buscar sentido para o que antes já estava pronto e fora de discussão. Que contemplou o gosto e a necessidade da leitura.

Essa leitura mágica, que transforma os homens, tem passado por sérios problemas, até mesmo é discutida a questão da "crise da leitura", que está mais presente na sociedade brasileira do que se imagina. Por vezes, as causas dessa crise passam despercebidas pela classe com menor poder de aquisição. Paulatinamente, a sociedade vai percebendo suas verdadeiras causas, que 
estão intimamente ligadas às questões políticas, econômicas e à estrutura social vigente, a capitalista, que se caracteriza pelo antagonismo de classes sociais, onde a classe dominante mantém o controle dos bens culturais, inclusive dos livros.

Silva analisa a crise da leitura em aspectos de privilégio de classes e injustiça social, afirmando que:

[...] o acesso à leitura e aos livros nunca conseguiu ser democratizado em nosso meio. A então propalada "crise da leitura" não é uma doença destas últimas décadas e nem deste século: ela vem sendo reproduzida desde o período colonial, juntamente com a reprodução do analfabetismo, com a falta de biblioteca e com a inexistência de políticas concretas para a popularização do livro (SILVA, 1986, p. 11-12).

Essas palavras demonstram explicitamente a realidade do Brasil, pois, em muitos aspectos, a nossa sociedade tem reproduzido situações semelhantes à que existia há séculos atrás, como a aprendizagem por memorização e repetição, feita pelos padres jesuítas no período de colonização, além da ainda insuficiente circulação de livros em todas as camadas da população.

Também Roger Chartier (1991), que escreve sobre o surgimento das práticas da escrita e da leitura, mostra que na Europa esse processo se desenvolve a partir do século XVI, com uma minoria que sabia assinar seu nome, e que essa revolução se dá primeiramente nas classes dirigentes - os clérigos e a elite -e, posteriormente, passou para as demais classes, quando os livros deixam de estar somente nas bibliotecas das igrejas e passam a ser reproduzidos em massa no século XVIII.

A crise da leitura presente é um fenômeno mundial e há muito tempo tem-se mostrado presente em nosso país. Nos anos do regime militar, mais recentemente, o Brasil passou por sérias crises, assim como outros países subdesenvolvidos, e a grande dívida externa contribuiu muito para isso. Nesse contexto, o acesso aos livros, assim como outros bens, se torna muito mais difícil para a classe trabalhadora, pois o custo para se adquirir um livro é muito alto e o salário muito baixo. Lembramos também que diversas livrarias fecharam as portas por falta de compradores.

Este cenário revela uma das causas da crise da leitura, que está relacionada ao custo, portanto, à economia, pois se o trabalhador não adquire livros, se não é leitor assíduo é, também, porque lhe faltam recursos. É evidente que isso ocorre, ou alguém poderá pensar que ele preferirá comprar um livro ao invés do alimento?

Assim, vai se fortificando o regime de privilégio. Ao mesmo tempo em que o pobre deixa de adquirir um livro porque seu poder aquisitivo não é suficiente para isso, a classe alta afirma sua superioridade cultural, com acervo na própria casa, com linguagem culta, com o conhecimento sobre diferentes assuntos, com o acesso às bibliotecas e com todos os benefícios que a leitura lhe proporciona.

Ter acesso a livros sempre foi uma regalia da classe com maior poder aquisitivo, certamente, devido aos problemas econômicos que enfrenta a classe baixa economicamente e o interesse em manter este último grupo alienado das relevantes questões sociais das quais fazem parte, como a política de distribuição de renda.

Como disse Silva (1986), a leitura é um importante instrumento de emancipação do homem. A apropriação igualitária dos saberes de algumas obras que revelam as bases da estrutura social vigente, aquelas de viés marxista, por exemplo, podem trazer à tona homens críticos, dispostos a lutarem por seus direitos.

Estudando a evolução da sociedade brasileira, Silva chegou à conclusão de que "a leitura é um importante instrumento para a libertação do povo brasileiro e para o processo de reconstrução de nossa sociedade" (SILVA, 1986, p. 11). Vale lembrar, essa conclusão é de alguém que presenciou um período muito crítico na sociedade brasileira na década de 
80, com autoritarismo, lutas e movimentos.

Não se considera apenas libertação para os trabalhadores que têm sua força de trabalho explorada pelo patrão. Ao contrário, a leitura também cria no ser humano um espírito criativo, curioso e descobridor, e faz com que ele não mais se contente em ler apenas textos obrigatórios, mas busque cada vez mais leituras prazerosas, que estimulem sua criticidade.

Dizer que a leitura é instrumento de libertação não significa também que seja qualquer leitura - e isso inclui a mecanizada - e sim uma leitura crítica, na qual o indivíduo, ao invés de apenas memorizar, é capaz de compreender, estabelecer relações com as situações práticas da vida e se posicionar frente aos desafios que lhe são postos. "A leitura crítica é condição para a educação libertadora, é condição para a verdadeira ação cultural que deve ser implementada nas escolas [e nas bibliotecas]" (SILVA, 1986, p. 51).

Esse desenvolver da criticidade faz com que se ampliem os horizontes do indivíduo, transformando-o em um novo ser pronto para enfrentar as condições que a sociedade lhe impõe e, assim, tornar-se um leitor assíduo, que encontra na leitura a base para sua autonomia.

Desde a infância, as pessoas precisam sentir o gosto que a leitura tem, e isso só é possível com o incentivo da família e de ações que a escola proporciona a elas. E para que esse gosto perdure, é preciso uma permanente busca, como pode ser visto nas palavras de Freire: "[...] a compreensão crítica da importância do ato de ler se veio em mim constituindo através de sua prática." (FREIRE, 1999, p. 16).

Ao se compreender o que realmente o ato de ler significa, constitui-se o prazer por usufruí-la. Porém, vale lembrar, não é só o prazer que se constitui, mas pode surgir um novo ser liberto, que é capaz de transformar a si e as condições que o cercam, pois a leitura nunca é um processo passivo ou neutro.
É para esses elementos que Silva chama a atenção. Ele diz: "a leitura - principalmente a leitura do texto literário - pode se constituir num fator de liberdade e transformação dos homens." (SILVA, 1986, p. 21). Nesta perspectiva, a leitura que defendemos é a que pode suscitar no leitor, também, o senso crítico, a fim de que se torne um escritor e cidadão que perceba sua realidade e seu contexto de uma forma mais crítica, mas que essa criticidade não fique só no terreno do discurso. Que nele seja inspirada a motivação pela luta e transformação social, que seja produtor de pensamentos novos, que saiba ir além de apenas reproduzir.

Para o poder dominante, quanto menos a população se apropriar do conhecimento acumulado ao longo da história, melhor. Isso explica o fato de que, mesmo a leitura sendo um direito de todos, é muito comum haver planos para que isso não ocorra. Nessa parcela que domina, encontramse os governos, que agem contra os interesses dos desprivilegiados, pois não investem em bibliotecas escolares e públicas e não promovem incentivo à leitura. Como expõe Silva: "as autoridades não estão interessadas em desenvolver o gosto pela leitura junto a todos os segmentos da população." (SILVA, 1986, p. 50).

As bibliotecas, ou a ausência delas, melhor dizendo, em muito contribuem para a crise da leitura, e muitas, quando existem, são esquecidas pelo órgão que deveria mantê-las. Em torno dos assuntos que a envolvem, pode-se também perceber a celeuma existente entre professores e bibliotecários. Segundo Silva (1986), são muitas as reclamações e idéias a priori que um tem do outro. O professor, não raro, ainda vê o bibliotecário como o "guardalivro", que em nada contribui para a formação dos alunos. Do mesmo modo, o bibliotecário acusa o professor por sua irresponsabilidade em não conhecer o acervo da biblioteca e pedir a "pesquisa escolar" aos alunos, em termos mal vistos, por ser destituída de informações prévias e do necessário acompanhamento. 
Enquanto esse antagonismo não for superado, a crise da leitura no país continuará como está. Enquanto professores e bibliotecários ficarem discutindo sobre a função de cada um e quem é o responsável pela falta de atitudes frente a esse desafio, a sociedade continuará desigual em termos do acesso à leitura.

O que tem ocorrido também é a delegação de responsabilidade entre escola e família na promoção da leitura. Os professores têm reclamado não só dos bibliotecários como das famílias por não contribuírem na formação das crianças.

Sabe-se que o que deve acontecer é a interação da família com a escola, para que o desempenho dos alunos seja satisfatório. A reunião escolar de pais e professores, por exemplo, importante meio de envolvimento dessas instituições, tem sido estigmatizada pela visão de que as reuniões só servem para cobranças e reclamações, provavelmente, sobre o comportamento dos filhos. Essa questão certamente deve ser posta pela escola aos pais, mas se deve também tomar cuidado para que isso não venha a ser o único motivo da convocação deles para virem à escola.

Por outro lado, a família não pode se isentar da vida escolar dos filhos e esquecer-se, de colaborar com a escola nesse trabalho. Tem sido comprovado que a família tem grande responsabilidade no bom e no mau desempenho dos alunos na escola e isso não deve ser ignorado por ela.

A primeira educação inicia-se em casa, com a aprendizagem informal, pois "não há melhor escola de formação cultural, social e psicológica que o próprio lar" (BALTAZAR; MORETTI; BATHAZAR, 2006, p. 45). Se a família der essa primeira base e ao longo dos anos dedicar-se à vida escolar dos filhos, certamente os mesmos terão uma formação mais adequada.

Esses são alguns desafios que devem ser superados, para que, juntos, professores, bibliotecários e família, possam desempenhar seu papel e colaborarem entre si na promoção de cidadãos leitores.

\section{Os Dados Coletados}

O período de observação em sala de aula, nesta pesquisa, teve a duração de uma semana em cada uma das três escolas, que se situam nos bairros e no centro da cidade, e podem ser consideradas de pequeno, médio e grande porte, respectivamente. Em cada escola, escolheu-se apenas uma sala de $4^{\mathrm{a}}$ série.

Percebeu-se que os professores se utilizam muito da leitura em coro de frases, números e palavras escritas no quadro negro, e também da divisão por colunas de carteiras para a leitura de texto impresso ou do quadro de giz.

Em uma das escolas, a leitura individual é tomada separadamente em outra sala, uma vez ao mês, e o aluno lê em voz alta um texto, e muitos alunos revelam dificuldades com a acentuação e entonação, como foi visto pela palavra "roxa", lida por quase todos como "rocha". Em seguida, a professora fez perguntas acerca da compreensão do texto e os elementos principais como título, nome dos personagens e suas características e o enredo. Percebeu-se que a maioria dos alunos respondeu após procurar no texto; alguns não conseguiram responder e poucos davam a resposta rapidamente. Não houve uma orientação ou feedback da professora aos alunos após essa atividade. A professora que acompanhava essas leituras avalia que: "alguns têm dificuldade, mas no geral entendem bem, até porque é apenas uma leitura".

Os métodos para o incentivo à leitura também foram observados. Na primeira escola, a professora auxiliar contou uma crônica de Sabino para os alunos e ao terminar disse: "Acabou!", mas os alunos coletivamente gritam: "Continua! Continua!”, um deles pede para então contar outra e a professora conta diversas fábulas para eles.

Esses alunos pareceram gostar muito de ouvir as histórias, só não aparentaram gostar de escrever, pois quando a professora pede o caderno de produção de texto os alunos gritam “nãooo!". A produção escrita que a professora solicitou deveria ser feita a partir 
de uma história em quadrinhos que ela entregou aos alunos.

Nessa escola, a professora e sua auxiliar criaram estratégias a cada bimestre, para a motivação para a leitura. Elas promoveram na turma no primeiro bimestre o projeto "Árvore da leitura", assim denominado porque os alunos recebem uma folhinha para colocarem na árvore com seu nome e o do livro lido, ao fundo da sala, toda semana. No segundo bimestre, a professora distribuiu livros de diversas séries e, após a leitura individual, fez sorteio de três alunos para contarem para a sala as informações relevantes sobre o livro e indicá-lo a alguma série.

No terceiro bimestre, três alunos, após a leitura do livro, prepararam em casa uma atividade para a turma, e deram uma mini-aula para os colegas. Esses projetos têm seguimento durante o ano todo. E no quarto bimestre, a iniciativa ficou por conta de: "Conte um conto", em que o aluno, escolhido com uma semana de antecedência, conta o enredo do livro lido para a turma.

Foi possível, durante as observações, apreciar esse último projeto, e ver que, apesar da vergonha e da voz baixa, os alunos gostam de participar. Uma particularidade observada foi que um aluno não estava contando a história com suas palavras, estava lendo, então a professora pediu para ele fechar o livro. O aluno não conseguiu continuar.

Notou-se, também, que nesse momento de leitura um aluno disse, de sua carteira, empolgado: "Professora, deixa eu ler o meu [livro]?" ao que, ligeiramente, a professora respondeu: "Não! Você não está escalado hoje". Outro aluno fez uma pergunta sobre o livro do colega, mas a professora pediu para ele não interromper.

Frente a essas observações, cabe perguntar: como os professores entendem leitura? A resposta para essa interrogação vai na mesma direção da que é dada à questão de como a leitura é proposta para os alunos, pois o professor pode aproximar ou afastar os alunos da leitura.
Que a resposta dessa professora não seja motivo de desânimo para quem acredita na educação brasileira, mas, ao contrário, deve servir para ajudar a despertar da acomodação tradicional de ensino. É preciso atingir a maior interação do professor e dos alunos com a leitura, e alcançar, assim, a compreensão crítica do ato de ler.

A "Hora do Conto", desenvolvida em outra escola, leva os alunos a se motivarem para ouvir a bibliotecária, uma vez na semana, narrar as histórias de literatura infantil e, em sala de aula, a professora se utilizou de classificados dos jornais para a leitura e produção de escrita.

$\mathrm{Na}$ terceira escola, a professora realiza com os alunos a "Hora da Leitura". Uma vez na semana, ela leva livros de uma determinada coleção, com quatro títulos diferentes. Os alunos lêem na sala e há atividade escrita acerca dos dados do livro (editora, autor, título, tradutor...), questões de compreensão e de criatividade (inventar outra capa, desenhar...)

Nabiblioteca, observou-se na escolaA, que existe um razoável acervo de livros, mas principalmente didáticos, juntamente com outros materiais como brinquedos, fitas de vídeo, representação do corpo humano, caixas com trabalhos feitos pelos alunos, troféus, retroprojetor, computador, televisor, mesa e cadeiras, fantoches e espaço para brincadeiras com alunos pequenos. Essa biblioteca tem o espaço de uma sala de aula, a funcionária responsável por ela não tem formação em nível superior e a porta é voltada para o corredor, o que causa muito barulho interno.

Na escola B, a biblioteca possui três estantes, uma para literatura infantil (empréstimo), outra para pesquisa (Enciclopédia) e outra de livros didáticos, revistas e dicionários (para os professores). A bibliotecária diz que o acervo não deixa a desejar, pois sempre há investimentos, e, na hora do recreio, vários alunos vêm à biblioteca, principalmente os pequenos que não sabem ler, mas interpretam as figuras. 
Na biblioteca da escola $\mathrm{C}$, o bibliotecário julga pobre o acervo para alunos do fundamental 1. Ela é grande e espaçosa, com estantes enormes, cheias de livros, e outras menores, para empréstimos, divididas de $1^{\mathrm{a}}$ a $4^{\mathrm{a}}$ série com livros de contos e revistas. Há muitos livros didáticos e de pesquisa, e também mesas com cadeiras, sofá, televisor e cestos com livros.

Nos corredores das escolas foram encontradas, quando existiam, apenas leituras curtas como orientações sobre higiene (lavar as mãos). No refeitório, há o cardápio semanal, dicas de bons modos e em uma das escolas, colada na parece a chamada "Dica do Dia", que fala sobre os benefícios do abacaxi e uma receita com essa fruta, além de uma pirâmide alimentar.

No ambiente de sala de aula, foram vistas, presas nas paredes, figuras geométricas, rosa dos ventos, árvore de papel, as letras do alfabeto e o mapa mundi. Apenas em uma sala não havia nenhuma imagem.

As observações se mostraram muito ricas em termos de realidade das escolas e ajudam a refletir a respeito de diversos aspectos da educação em ações que proporcionem melhorias na escola e na relação professor-aluno e professor-aluno-leitura.

Apresentamos, agora, os dados obtidos por meio dos questionários e os comentários a respeito. Primeiramente, dos alunos; posteriormente, dos professores, tratando-se de cada questão apresentada no questionário, que, no caso dos alunos, foram seis: duas objetivas, duas objetivas com comentário dos alunos, uma no formato Likert e uma dissertativa. As escolas, lembramos, serão nomeadas pelas letras A, B e C.

A primeira pergunta, "Você gosta de ler?" é bem direta e traz uma resposta muito significativa para a questão dos alunos gostarem ou não de leitura, pois é observado no gráfico abaixo que, entre todos os alunos pesquisados, são inexistentes resultados para o "não gostar de leitura". Em média, 55,24\% demonstraram gostar de ler e o restante afirmou gostar pouco, porque lê pouco.

Gráfico 1. O gosto pela leitura na $4^{\mathrm{a}}$ série do ensino fundamental.

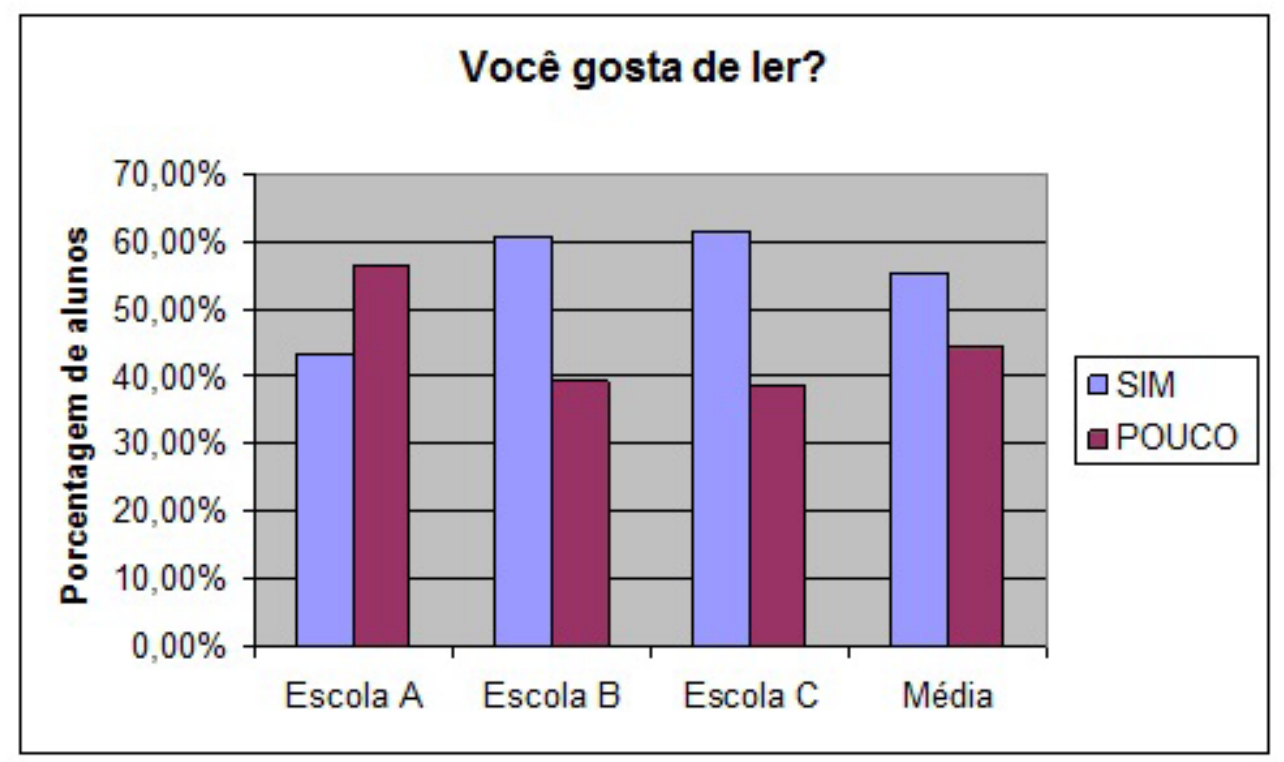

Fonte: Do Autor 
Esses dados surpreendem, pois se tinha como pressuposto o desinteresse pela leitura nessa série $\left(4^{\mathrm{a}}\right)$. Revela-se, portanto, que o gosto de ler é existente em mais da metade dos alunos, por isso, é fundamental a insistência, por parte das instituições próximas do aluno, em aproximá-los cada vez mais do mundo da leitura, para que esse gosto não se venha definhar, mas, ao contrário, que esses alunos venham a tornar-se adultos leitores.

Muitos deles responderam que gostam "mais ou menos" de ler. São aqueles alunos que já experimentaram a leitura prazerosa, mas que não é exercitada cotidianamente. Eles talvez não tenham um estimulo necessário em casa ou na sala de aula para continuarem a buscar, cada vez mais, a leitura como algo satisfatório. O gosto pela leitura nem sempre é despertado espontaneamente na criança, daí o importante papel das instituições presentes na vida dela.

Quando se descobre o prazer pela leitura, seja criança ou adulto, o indivíduo sai da condição de espectador e consegue perceber sua realidade até o momento de "começar a ler para enxergar melhor o mundo" (SILVA, 1995, p. 13). Daí, torna-se cada vez mais difícil de ignorar a vontade por essa prática de libertação e satisfação.

O próximo gráfico se refere à pergunta: "Você já leu algum livro por seu interesse, sem que o (a) professor (a) tenha pedido para ler?". É muito comum que os professores ofereçam sugestões de leitura e boa parte dos alunos realize apenas essas indicações, porém 94,36\% deles demonstraram que lêem livros por vontade própria, sem que o professor peça.

Gráfico 2. Porcentagem de alunos da $4^{\mathrm{a}}$ série que procuram livros espontaneamente.

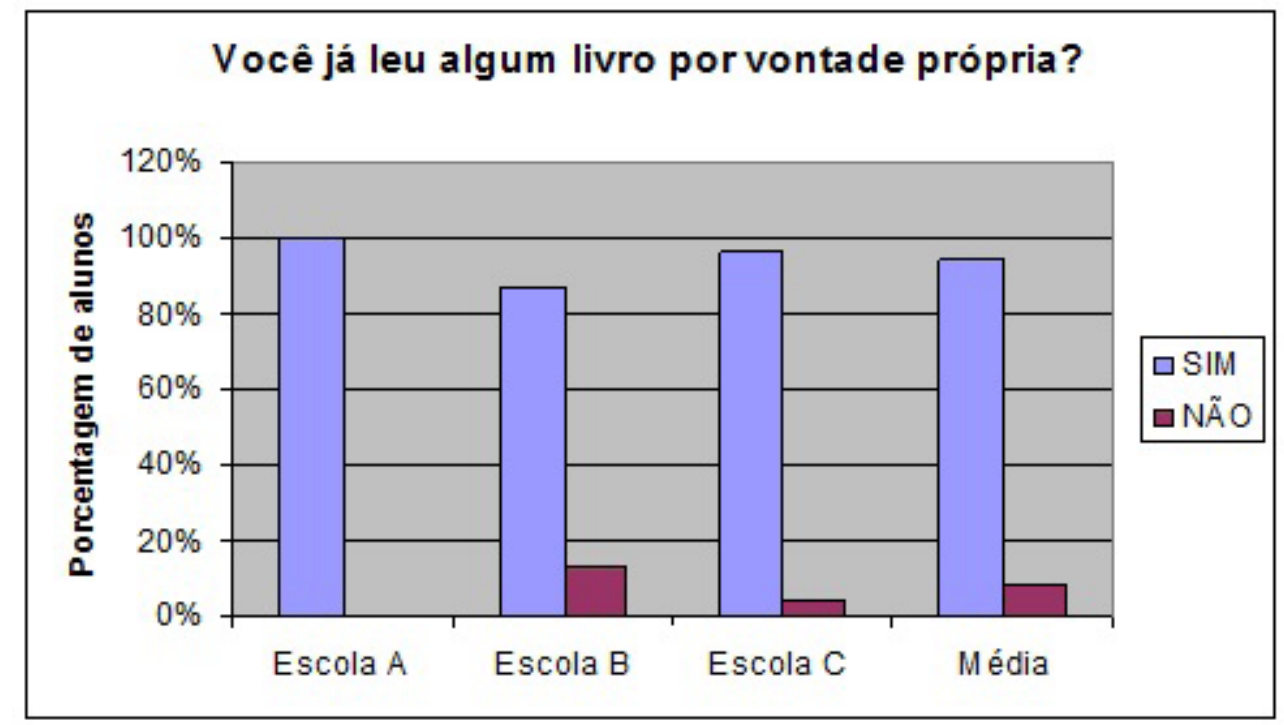

Fonte: Do Autor

Esses números indicam, satisfatoriamente, que os alunos da $4^{\mathrm{a}}$ série têm exercido a liberdade de buscar recursos que lhe sejam agradáveis, como os livros e isso deve ser levado em conta pelos mantenedores das bibliotecas, para que o acervo seja sempre melhorado e ampliado e, assim, se possa cultivar a curiosidade dos alunos em ler livros ainda não lidos. 
Muitos alunos escolhem os livros não obrigatórios pelo título, pela ilustração da capa ou por indicação de outro colega, outra razão para a boa escolha na compra dos livros.
Na questão seguinte, "Que valor você atribui à importância da leitura em sua vida?" pediu-se que o aluno marcasse o grau de importância da leitura na sua vida, indo do pouco ao altamente significativa.

Quadro 1. Valores atribuídos à importância da leitura para os alunos da $4^{\mathrm{a}}$ série em formato Likert.

\begin{tabular}{|lccccc|}
\hline & \multicolumn{5}{c|}{ Importância da leitura na vida dos estudantes da $4^{\text {a }}$ série. } \\
\cline { 2 - 6 } Escola & 1. Pouco & 2. Regular & 3.Significativa & 4. Muito Significativa & 5. Altamente Significativa \\
\hline A & $3,33 \%$ & $20 \%$ & $20 \%$ & $30 \%$ & $26,66 \%$ \\
B & $4,34 \%$ & $17,39 \%$ & $17,39 \%$ & $39,13 \%$ & $21,73 \%$ \\
C & 0 & $15,38 \%$ & $19,23 \%$ & $38,46 \%$ & $26,92 \%$ \\
MÉDIA & $3,83 \%$ & $17,59 \%$ & $18,87 \%$ & $35,86 \%$ & $25,10 \%$ \\
\hline
\end{tabular}

Fonte: Do Autor

Pode-se perceber que a maioria marcou as duas últimas opções. Isso se dá em razão do fato de que a leitura é, indiscutivelmente, importante para as pessoas, elas sabem disso, e estão prontas a testemunharem a favor dessa verdade. Deve-se atentar, no entanto, para a concreta prática dessa leitura, para a presença significativa dela na vida das pessoas, principalmente das crianças.

É como escovar os dentes, todos sabem de sua fundamental importância, mas para que de fato se torne um hábito, tem que ser ensinado e praticado desde a infância.

Considerando a proximidade entre "muito significativa" e "altamente significativa", ao juntar esses dois valores pode-se perceber uma média de $30,48 \%$ de alunos, que dão essa importância para a leitura em suas vidas.

Questionou-se também o que os alunos entendem por leitura, com a questão "Para você, o que é leitura?" e verificou-se que as respostas se apresentaram bem diversificadas. Na tabela adiante, seguem, classificadas por ordem alfabética, as referidas respostas, encontradas nas três escolas pesquisadas, que estão localizadas nos bairros e no centro da cidade, são de porte pequeno, médio e grande, respectivamente, com um total de 79 discentes, entre 9 e 12 anos, sendo 30 deles da escola A, 23 da escola B e 26 da C. Dentre todos os alunos, $54,43 \%$ são do sexo masculino, e, na escola $\mathrm{A}$, eles representam $66,66 \%$; na escola B são 47,82\%; e na C, $46,15 \%$.

Salienta-se a leitura como forma de aprender, tanto o aprendizado formal quanto ao considerado para a vida, como maneira de melhorar a inteligência, como algo muito importante, divertido, "legal", que serve para melhorar o desempenho da leitura e escrita, ou, simplesmente, leitura significa "ler". 
Quadro 2. Justificativas de respostas para a conceituação da palavra "leitura"

\begin{tabular}{|c|c|c|c|}
\hline \multirow{2}{*}{$\begin{array}{l}\text { Para você, o que é leitura? } \\
\text { RESPOSTAS }\end{array}$} & \multicolumn{3}{|c|}{ Escolas } \\
\hline & $\mathbf{A}$ & B & $\mathbf{C}$ \\
\hline Aprendizado acadêmico / Inteligência / Sabedoria & 6 & 7 & 9 \\
\hline Atenção & 2 & 0 & 0 \\
\hline Aventura & 1 & 0 & 0 \\
\hline Compreensão do texto / interpretação & 1 & 0 & 1 \\
\hline Diversão & 2 & 2 & 2 \\
\hline É bom / Legal & 0 & 6 & 0 \\
\hline É ler & 5 & 0 & 2 \\
\hline Enredo & 0 & 0 & 1 \\
\hline Fonte de criatividade, imaginação e descoberta & 1 & 0 & 0 \\
\hline Imagens & 0 & 0 & 1 \\
\hline Interessante / interesse próprio & 3 & 0 & 0 \\
\hline Maior conhecimento sobre ortografia / escrita & 1 & 0 & 1 \\
\hline Maneira de aprender / Aprendizado para a vida & 4 & 10 & 6 \\
\hline Melhora o desempenho da leitura (qualidade) & 1 & 0 & 2 \\
\hline Melhora o desempenho da leitura (velocidade) & 0 & 1 & 1 \\
\hline Modo de comunicação / informação & 0 & 1 & 1 \\
\hline Modo de passar o tempo & 1 & 0 & 0 \\
\hline Muito importante / significativo / especial / Fundamental & 6 & 5 & 3 \\
\hline Palavras que contam uma história / que despertam interesse & 1 & 3 & 2 \\
\hline Saber contar a história lida & 1 & 0 & 0 \\
\hline Treinamento & 0 & 0 & 1 \\
\hline Viagem & 0 & 0 & 1 \\
\hline Em branco & 2 & 0 & 3 \\
\hline
\end{tabular}

$\mathrm{Na}$ segunda parte do questionário, o aluno respondeu à pergunta "Você vai sempre à biblioteca?" e "Se vai, em média quantas vezes por mês?" com a intenção de conhecer a freqüência de idas a esse espaço e, mais que isso, de observar a questão do acesso ao mundo da leitura, pois hoje a biblioteca escolar é veículo de promoção de leitura, que não era tão comum há algumas décadas, marcadas pela desigualdade de acesso aos livros em nossa sociedade.

Vê-se na primeira tabela que, em média, mais de $65 \%$ dos alunos pesquisados dizem ir sempre à biblioteca, e a segunda tabela mostra que a quantidade mensal dessas idas é variada, indo de uma a quinze, mas a referência quatro, sem dúvida, foi a mais indicada por eles. 
Quadro 3. Porcentagem de respostas para "ir sempre ou não à biblioteca"

\begin{tabular}{|llcc|}
\hline \multirow{2}{*}{ ESCOLA } & \multicolumn{3}{c|}{ Você vai sempre à biblioteca? } \\
\cline { 2 - 4 } & SIM & NÃO & EM BRANCO \\
\hline A & $60 \%$ & $40 \%$ & 0 \\
B & $69,52 \%$ & $30,43 \%$ & 0 \\
MÉDIA & $69,23 \%$ & $15,38 \%$ & $15,38 \%$ \\
\hline
\end{tabular}

Fonte: Do Autor

Quadro 4. Quantidade de idas por mês à biblioteca

\begin{tabular}{|llll|}
\hline Vai sempre a biblioteca? & \multicolumn{3}{c|}{ Quantas vezes por mês? } \\
\cline { 2 - 4 } Quantidade de idas à biblioteca/mês & Escola A & Escola B & Escola C \\
\hline 1 & 0 & 2 (alunos) & 0 \\
2 & 1 (aluno) & 3 (alunos) & 0 \\
3 & 1 (aluno) & 0 & 0 \\
4 & 13 (alunos) & 13 (alunos) & 16 (alunos) \\
5 & 1 (aluno) & 1 (aluno) & 1 (aluno) \\
6 & 2 (alunos) & 0 & 0 \\
7 & 1 (aluno) & 0 & 1 (aluno) \\
8 & 2 (alunos) & 2 (alunos) & 0 \\
9 & 1 (aluno) & 0 & 0 \\
10 & 1 (aluno) & 0 & 0 \\
12 & 0 & 1 (aluno) & 0 \\
15 & 1 (aluno) & 0 & 0 \\
Em branco & 1 (aluno) & 0 & 6 (alunos) \\
Média no mês & & 4 Vezes & \\
\hline
\end{tabular}

Fonte: Do Autor

Quadro 5. Respostas para a questão das idas à biblioteca que apontam um ou outro número.

\begin{tabular}{|llll|}
\hline OUTRAS RESPOSTAS & \multicolumn{3}{c|}{ Alunos por escola } \\
\cline { 2 - 4 } & A & B & C \\
\hline "4 ou 5 vezes" & 2 & 0 & 1 \\
"Poucas vezes" & 0 & 0 & 0 \\
"1 vez por ano" & 0 & 1 & 0 \\
"Quase nenhuma vez" & 1 & 0 & 0 \\
"10 ou 11 dias por mês" & 1 & 0 & 0 \\
\hline "Eu vou a biblioteca" & 1 & 0 & 1 \\
\hline
\end{tabular}

Fonte: Do Autor 
Por que o número quatro (4 vezes ao mês) apareceu com maior freqüência? É corriqueiro nas escolas, que se estabeleça um dia na semana para que os alunos possam ir à biblioteca escolar para renovar livro ou fazer novo empréstimo. Esse número, portanto, acaba sendo o mais comum entre os alunos, pois muitos não sentem curiosidade de explorar mais a biblioteca ou ir mais vezes que o obrigatório.

Destacam-se, porém, alguns alunos que dizem ir mais que quatro vezes ao mês - quatro alunos responderam ir oito vezes/mês à biblioteca - ou, o que é de estranhar, menos - há quatro respostas para duas idas à biblioteca/mês.

Outra análise pode ser feita. Para os alunos que participaram dessa pesquisa e responderam ir quatros vezes/mês à biblioteca, essa quantidade de idas significa para eles "ir sempre" à biblioteca? $16,45 \%$ desses alunos consideram que ir quatro vezes à biblioteca/mês é pouco, pois, ao responderem se vão sempre à biblioteca, marcaram a alternativa "não" e disseram ir quatro vezes/mês. Isso significa que, para esses alunos, ir somente a quantidade de vezes que é exigida pela escola é insuficiente. Eles sabem que "ir sempre" à biblioteca é ir além do que é pedido, porém vão apenas essas mesmas quatros vezes/mês.

Entre os que responderam não ir sempre à biblioteca, há uma resposta interessante, pois o aluno diz ir à biblioteca nove vezes/mês. Certamente, esse aluno já é um leitor, pois considera que ir nove vezes/ mês à biblioteca ainda não é o suficiente. Há que se ter esperança que outros alunos também vejam a biblioteca como um espaço seu, de descoberta e prazer, para que as idas até ela se revelem cada vez mais gostosas e estimulantes.

Esses resultados revelam que os alunos entendem que ir à biblioteca o mínimo exigido pela escola é pouco. Vejamos, agora, os dados que revelam o contrário.

$32,91 \%$ desses alunos consideram que ir quatro vezes à biblioteca/mês significa "ir sempre". Ou seja, aquela rotina semanal de visita à biblioteca é o necessário para se dizer que vai sempre, mostrando que nesses alunos ainda não foi despertada a vontade de se aproximar mais da biblioteca, de entender que esse é um lugar onde se podem fazer descobertas e viajar para onde se quiser. Esse gosto pela autonomia de buscar por si só as leituras que dêem prazer, parece não ter sido ainda despertado. Vê-se, então, uma limitação do aluno ao fazer apenas o que lhe é exigido. Mas, o que é ainda mais constrangedor, é que dois alunos da escola $\mathrm{B}$, que marcaram "ir sempre" á biblioteca, vão apenas uma vez/mês; três alunos dessa mesma escola, que também disseram ir sempre à biblioteca, responderam ir duas vezes/ mês e um aluno da escola $\mathrm{A}$ diz ir três vezes/mês à biblioteca e, também consideram que isso significa ir sempre. Esses alunos estão a nos dizer que ir menos que uma vez por semana à biblioteca é o suficiente.

Há também respostas para a quantidade de idas à biblioteca como: "poucas vezes", "1 vez por ano" e "quase nenhuma vez". São alguns dados assustadores, que se revelam nos bancos escolares.

Quem e quantos são esses alunos? Esses alunos estão presentes nas escolas do Brasil inteiro, por certo, destituídos do prazer e do beneficio da leitura. São os mesmos que não suportam as aulas de leitura, que quando vão à biblioteca procuram qualquer outra coisa para fazer, diferente de ler, e que em sala de aula ou em casa "torcem o nariz" quando são chamados para fazer leitura.

Eles, provavelmente, ainda não sabem o gosto que a leitura tem, e que tanto precisa ser despertado neles. Cabe enfatizar que, principalmente, os professores e a família têm grande contribuição nesse processo.

Em se tratando de sala de aula, como diz Rezende, é observado que "as muitas vezes, enfadonhas aulas de literatura ou de leitura acabam matando o prazer do texto e, pior que isso provocando o aborto de um leitor em potencial" (REZENDE, 2007, p. 29). Mas isso, por vezes, também é devido à escolha dos textos que serão utilizados. 
O professor precisa criar estratégias que despertem o interesse do aluno pela leitura sugerida, pois é o primeiro passo para que o aluno, posteriormente, saia das "asas" do professor e por vontade própria busque materiais de leitura.

E claro, o professor não é a única pessoa responsável por incutir na criança a vontade de ler, a família deve estar sempre atenta para que, desde a infância, ela tenha em casa, além de bons exemplos - pais que lêem -, livros à sua disposição, que inclusive podem ser comprados já usados e, portanto, por preços mais acessíveis. Dessa forma, poderão ser encontrados mais alunos que vão sempre às bibliotecas, tanto escolares como públicas, às livrarias e porque não à internet, procurando leituras, que serão tema de discussões entre os colegas mais tarde.

Ainda no que diz respeito às bibliotecas, a última questão: “Que livros você procura na biblioteca?" Com alternativas "Só os que o (a) professor (a) pede" ou "Outros que gosto de ler" revela a porcentagem de alunos que ao irem à biblioteca não se limitam em emprestar apenas os livros que o (a) professor (a) pede, e por meio do questionamento "Se você procura na biblioteca outros livros que gosta de ler, diga quais", foi possível saber a respeito dos livros procurados espontaneamente, vistos no próximo quadro.

Quadro 6. Porcentagem de respostas para o tipo de material de leitura procurado na biblioteca.

\begin{tabular}{|lccc|}
\hline & \multicolumn{3}{c|}{ Que livros você procura na biblioteca? } \\
Escola & Só os que o (a) professor (a) pede. & Outros livros que gosto de ler. & EM BRANCO \\
\hline A & 0 & $100 \%$ & 0 \\
B & $4,34 \%$ & $95,65 \%$ & 0 \\
C & $7,69 \%$ & $88,46 \%$ & $3,84 \%$ \\
MÉDIA & $6,01 \%$ & $94,70 \%$ & $3,84 \%$ \\
\hline
\end{tabular}

Fonte: Do Autor

Esses dados se revelam animadores, pois mais de $90 \%$ do total de alunos que participaram da pesquisa dizem procurar na biblioteca não só os livros indicados pelo professor, como também outros livros, por interesse próprio. Esses outros livros, que os alunos gostam de ler, são indicados por eles no quadro 7, e podem ser tomados como sugestões para professores e pais, que planejam propor leituras prazerosas, desprovidas de cobrança, para seus alunos e filhos. Tem-se como destaque as histórias em quadrinhos, que tanto prendem a atenção das crianças.

Essas leituras prazerosas se dão, como foi observado, nas escolas, por meio da liberdade dos alunos na biblioteca. Há, por exemplo, uma escola, que, após a renovação ou empréstimo de livros, estabelece um espaço de tempo para que os alunos escolham livros, gibis etc., para lerem ali mesmo e muitos lêem vários nesse período.

Toda semana então, durante o tempo na biblioteca, os alunos podem desfrutar do acervo e assim, fazer crescer a curiosidade e vontade de ler mais livros, que, normalmente, são escolhidos pelo criativo título ou pela ilustração da capa. É um momento de quebra de rotina. Um momento de espontaneidade dos alunos, que se vêem imersos em tanta possibilidade de exploração, podendo deixar extrapolar a curiosidade pelos temas desconhecidos.

A variedade de materiais de leitura é grande e pode ser utilizada pela escola para incentivar o aluno nessa busca, como já disse Rezende: “[...] em um mundo de múltiplos textos, não há razão 
Quadro 7. Lista de livros indicados pelos alunos que são procurados espontaneamente.

\begin{tabular}{|c|c|c|c|}
\hline Livros procurados espontaneamente & $\mathbf{A}$ & B & $\mathbf{C}$ \\
\hline Ação & 2 (alunos) & 1 (aluno) & 2 (alunos) \\
\hline Aventura & 5 (alunos) & 0 & 4 (alunos) \\
\hline Bíblicos & 0 & 2 (alunos) & 0 \\
\hline Ciência & 0 & 1 (aluno) & 0 \\
\hline Coleção & 1 (aluno) & 0 & 0 \\
\hline Com título curioso e diferente & 0 & 1 (aluno) & 0 \\
\hline Comédia & 3 (alunos) & 5 (alunos) & 2 (alunos) \\
\hline Contos & 1 (aluno) & 2 (alunos) & 0 \\
\hline Curiosidades & 1 (aluno) & 0 & 0 \\
\hline De pesquisa & 0 & 1 (aluno) & 0 \\
\hline Fábulas / Conto de fadas & 1 (aluno) & 1 (aluno) & 1 (aluno) \\
\hline Grandes & 1 (aluno) & 1 (aluno) & 1 (aluno) \\
\hline Gregos & 2 (alunos) & 0 & 0 \\
\hline História em quadrinhos / Gibis / Desenho animado & 7 (alunos) & 20 (alunos) & 18 (alunos) \\
\hline Ilustrados & 0 & 1 (aluno) & 0 \\
\hline Interessante / legal & 3 (alunos) & 0 & 2 (alunos) \\
\hline Jornal & 0 & 1 (aluno) & 0 \\
\hline Literatura infanto juvenil & 10 (alunos) & 3 (alunos) & 3 (alunos) \\
\hline Livros antigos / sobre o passado / histórico & 3 (alunos) & 2 (alunos) & 0 \\
\hline Poesia & 1 (aluno) & 0 & 1 (aluno) \\
\hline Próprios da série $\left(4^{\circ}\right)$ & 1 (aluno) & 0 & 0 \\
\hline Sobre a Terra & 0 & 1 (aluno) & 0 \\
\hline Sobre carros & 1 (aluno) & 0 & 0 \\
\hline Suspense & 1 (aluno) & 0 & 0 \\
\hline Tecnologia & 0 & 1 (aluno) & 0 \\
\hline Terror / Guerra / Monstro & 2 (alunos) & 1 (aluno) & 2 (alunos) \\
\hline Todos os tipos & 1 (aluno) & 1 (aluno) & 0 \\
\hline Em branco & 1 (aluno) & 1 (aluno) & 6 (alunos) \\
\hline
\end{tabular}

Fonte: Do Autor

para não explorarmos na escola, na academia, essa diversidade textual, quando se trata do processo de ensino e aprendizagem e, particularmente, quando se tem o propósito de formar leitores." (REZENDE, 2009, p. 46)
A ida espontânea dos alunos à biblioteca em busca de outros gêneros ou materiais de leitura que não são os exigidos pelo professor é vista como feita por alunos que já são leitores. Por isso, a escola deve cuidar para que não ocorra um desestímulo 
desses alunos. Além disso, cabe a ela definir o planejamento de ações que envolvam outros alunos que não possuem o mesmo hábito.

O outro questionário foi respondido por seis professoras nas três escolas e das seis perguntas contidas no questionário, foram selecionadas, para a apresentação dos dados, as quatro que são pertinentes para este trabalho. Para a primeira questão, "Professor (a), como você interage com seus alunos em relação à leitura?" obtiveram-se as seguintes respostas sintetizadas:

Quadro 8. Interação Professor-aluno-leitura

\section{Professor (a), como você interage com seus alunos em relação à leitura?}

\section{Escola A}

- Através de Projetos

- Com orientação quanto à pontuação e entonação e após leitura verificação da compreensão.

- Professores e alunos lêem e contam histórias.

\section{Escola B}

- Com incentivo à leitura

- Professora lendo junto com os alunos; comentando os textos; dando sugestões de livros e oferecendo materiais de leitura.

\section{Escola C}

- Trazendo novidades (jornal, revista, folhetos); lendo para a turma e conversas sobre o texto lido.

Fonte: Do Autor

Observa-se que, nas três escolas, as seguinte, "Como você julga o desempenho de professoras dizem que ler para os alunos e com os alunos é uma forma de interação com eles em seus alunos em relação à leitura", é uma análise relação a leitura, praticada por elas. A pergunta da professora em relação aos alunos: 
Quadro 9. Justificativas de respostas dos professores em relação ao desempenho de leitura de seus alunos.

\section{Como você julga o desempenho de seus alunos em relação à leitura?}

Bom - Razoável - Precário. Justifique.

\section{Escola A}

- Bom. Não pode ser considerada ótima leitura, pois uma parte dos alunos possui vícios de linguagem e não se concentra.

- Bom. A maioria respeita pontuação e entende o texto.

- Bom. Boa leitura; gostam de ler, contar e ouvir histórias.

\section{Escola B}

- Bom. Esforço em aprender mais e gosto pela leitura.

- Razoável. “Tenho percebido que de um modo geral as crianças não tem interesse pela leitura, necessitam de muito estímulo tanto da escola quanto da família.” (fala na íntegra de uma das professoras)

\section{Escola C}

- Bom. "Alguns alunos lêem muito bem, interpretam, e consequentemente produzem ótimos textos." (fala na íntegra de uma das professoras)

Fonte: Do Autor

Entende-se que para a maioria dessas relação à leitura pela falta de interesse. A próxima professoras, seus alunos gostam de ler e lêem bem, questão, "Você percebe iniciativa dos seus alunos consequentemente, contam e escrevem também, em procurar material de leitura? Como isso se mas têm dificuldades com os vícios de linguagem e manifesta?" se refere à iniciativa dos alunos na a concentração. Apenas na escola B uma professora busca de leitura, que já foi respondido por eles e julga ser razoável o desempenho de seus alunos em agora também por seus professores:

Quadro 10. Justificativas de respostas referentes a iniciativa do aluno em procurar material de leitura.

\section{Você percebe iniciativa dos seus alunos em procurar material de leitura? Como isso se manifesta?}

\section{Escola A}

- Não de todos. Mas quando encontram livros interessantes há um alvoroço para ler.

- Sim. "Os alunos procuram a biblioteca semanalmente e muitos trazem material de leitura de casa ou comentam sobre o que leram (livro, reportagem, Historia em quadrinhos)." (fala na íntegra de uma das professoras)

- Quando procuram os livros e assuntos comentados e pedem histórias.

\section{Escola B}

- Sim. Quando é colocado livros à disposição deles e quando chegam com materiais de leitura.

- Não. "Ultimamente nem na biblioteca eles se interessam em ir. Quando vão ficam bagunçando."

\section{Escola C}

- A maioria da turma mostra interesse. Eles gostam dos livros, trazem material de casa e trocam entre eles. Concentração e comentários da leitura.

Fonte: Do Autor 
De acordo com essas professoras, a maioria tem iniciativa pela leitura, se empolga por um livro interessante, comenta sobre o que foi lido e trazem de casa materiais de leitura também. Uma delas, no entanto, fala da realidade vista nas idas à biblioteca, caracterizada pelo desinteresse e baderna.
A última questão apresentada: "o que você julga necessário para motivar seus alunos a lerem mais?" pede que o professor explicite algumas ações para motivar os alunos no sentido de lerem mais frequentemente:

Quadro 11. Justificativas de respostas acerca da motivação do aluno para a leitura.

\section{O que você julga necessário para motivar seus alunos a lerem mais?}

\section{Escola A}

- "Projetos interessantes que despertem nas crianças o interesse pela leitura." (fala na íntegra de uma das professoras)

- Através de exemplos, oferecendo oportunidades e diferentes tipos de texto. Despertar o gosto pela leitura. - "Selecionar material, obras especificas e adequadas aos alunos." (fala na íntegra de uma das professoras)

\section{Escola B}

- “Ler muito pra eles. Mostrar como é bom 'mergulhar' num mundo diferente.” (fala na íntegra de uma das professoras)

- "Leituras de textos que sejam do interesse deles, ler um livro em vários dias deixando sempre um suspense no ar, momentos de leitura que não tenham cobrança." (fala na íntegra de uma das professoras)

\section{Escola C}

- Apresentar leituras interessantes, de vários assuntos, com ilustrações e curiosidades.

Fonte: Do Autor

Essas são algumas iniciativas interessantes, que podem auxiliar o desenvolvimento do gosto pela leitura nos alunos, e, juntamente com uma teoria consistente, que auxilie a compreender o valor dessa atividade. Certamente com o auxílio de toda a equipe escolar, as ações terão sentido e serão possíveis resultados significativos na vida dos alunos e na de todos os envolvidos nesse processo.

\section{Considerações Finais}

A pesquisa oferece contribuição para a compreensão da leitura na $4^{\mathrm{a}}$ série, uma vez que revelou que a maioria desses alunos $(55,24 \%$ de 79 estudantes) gosta de ler, considera a leitura muito/ altamente significativa $(30,48 \%)$ e procura materiais de leitura espontaneamente $(94,36 \%)$.

Esses resultados, ainda que não de todo satisfatórios do ponto de vista da formação de leitores, apontam para o prazer pela leitura existente nesses alunos. Uma vez considerado o prazer em ler como a interação do leitor com o texto,e essa interação caracteriza-se como uma atração tão recíproca que motiva o leitor pela busca constante de fontes de leitura, percebe-se o satisfatório encontro dos alunos com a palavra escrita.

Por meio também da livre procura de livros, ou seja, do aluno poder entrar na biblioteca e se deliciar/envolver com o que mais lhe agradar, é possível notar em geral o gosto no desenvolvimento desse hábito. Outra característica marcante é a empolgação dos alunos em ouvir as histórias e os contos.

Apesar de se poder dizer que o gosto/prazer em ler existe nesses alunos, infelizmente ele não está presente em todos eles. Admite-se que esses dados 
precisam ser melhorados, não somente em termos quantitativos, mas, sobretudo, qualitativos, por se encontrar muitos alunos (44,75\%) ainda na fase de "gostar mais ou menos" de ler e professores que ainda não conseguem auxiliar plenamente seus alunos nessa tarefa.

Por meio das observações nas salas de aula, notou-se que os professores consideram importante a leitura e desenvolvem projetos para incentivar seus alunos e que os mesmos gostam de participar dessas propostas. Porém, alguns professores se limitam a uma atividade mecanizada e sem propósito aparente, e não dão espaço para os alunos exporem suas curiosidades e espontaneidades. Esses professores alegam que precisam cumprir as atividades estabelecidas, como foi visto na fala da professora que não deixou o aluno contar a historia do livro que leu, porque ele não estava "escalado" para isso naquele dia.

Vivenciamos a primeira década do século XXI, estamos cada vez mais envoltos pela leitura e isso faz lembrar da necessidade de frequentemente atentarmos para o ato de ler, e aqui, especialmente, para a leitura desenvolvida na escola e que deve continuar ao longo da vida dos educandos, sendo um ato que além de satisfação, proporciona a descoberta e a emancipação.

Os professores participantes da pesquisa consideram que a maior parcela de seus alunos vai bem em termos de leitura. No entanto, ainda há muitos estudantes que estão condicionados às leituras obrigatórias e desprovidas de significado, pois ainda se vêem nas escolas textos oferecidos pelo professor que não são bem vindos no universo dos alunos. Por isso, o docente precisa escolher os textos de tal forma que atraiam o aluno para um momento significativo e não para passar o tempo, ou estritamente para atribuir um valor, pois isso pode gerar desinteresse pelo ato de ler. Se isso acontece, os alunos podem acabar vendo o ato de ler apenas como forma de adquirir nota, tornandose uma atividade cansativa e destituída de sentido.
A ida às bibliotecas tem refletido esse desinteresse, pois muitos alunos só vão até ela porque é rotina a ida semanal para renovar ou emprestar livros.

É necessária uma constante atenção de toda a equipe escolar no sentido de favorecer o encontro do aluno com leituras que lhe despertem o interesse, sem a preocupação com atribuição de valor numérico, por exemplo, pois os alunos que já se interessam pela leitura podem cada vez mais desenvolver esse hábito. Quem ainda não tem esse gosto, passa a ter uma oportunidade para achegar-se a esse mundo de incríveis descobertas.

Descobertas essas que, tanto levam para lugares distantes, como mostra a realidade à frente dos olhos do leitor, que se faz na presença do outro, inclusive quando esse outro é um autor. Neste sentido, a leitura crítica pode ser desenvolvida por meio de sua prática freqüente, que precisa ser estimulada desde a infância pelos indivíduos participantes da vida da criança/aluno.

\section{Agradecimentos}

À professora doutora Lucinéa Aparecida de Rezende, que orientou o processo dessa pesquisa, inclusive na elaboração deste artigo.

À Secretaria de Educação do município, por ter me proporcionado a entrada nas escolas.

Às escolas participantes da pesquisa que me aceitaram de modo tão gentil.

À professora Ana Lucia Ferreira Aoyama, da disciplina de Pesquisa Educacional, que também me auxiliou na organização deste trabalho.

\section{Referências}

BALTAZAR, José Antonio; MORETTI, Lucia H. Tiosso; BALTHAZAR, Maria Cecília. Família e escola: um espaço interativo e de conflitos. São Paulo: Arte \& Ciência, 2006.

BARTHES, Roland. O prazer do texto. São Paulo: Perspectiva, 1973. 
CHARTIER, Roges (Org.). As práticas da escrita. In: ARIÈS, Philippe; CHARTIER, Roges. História da vida privada: da renascença ao século das luzes. 3. ed. São Paulo: Companhia das Letras, 1991. p. 113-161.

FREIRE, Paulo. A importância do ato de ler, em três artigos que se completam. 38. ed. São Paulo: Cortez, 1999.

REZENDE, Lucinea Aparecida de (Org.). Leitura e visão de mundo: peças de um quebra cabeça. Londrina: EDUEL, 2007.

. Leitura e formação de leitores: vivências teórico práticas. Londrina: EDUEL, 2009.

SILVA, Ezequiel Theodoro. A produção da leitura na escola: pesquisas X propostas. São Paulo: Ática, 1995.

Leitura na escola e na biblioteca: leitura e conscientização. Campinas: Papirus, 1986. 


\section{APÊNDICE A}

Questionário dos alunos

Caro aluno(a), pedimos sua colaboração no sentido de responder às questões abaixo. Por gentileza, responda às questões da maneira mais completa que puder. Suas respostas auxiliarão a compreender melhor o trabalho com a leitura. Você também tem a opção de não responder, e sua identidade será totalmente preservada.

Escola:

Idade: Série:

Masculino

Feminino

\section{BLOCO I}

\section{LEITURA EM GERAL}

1.1 Você gosta de ler?

1.2 Você já leu algum livro por seu interesse, sem que o (a) professor (a) tenha pedido para ler?

1.3 Que valor você atribui à importância da leitura em sua vida? Marque o numero que corresponda à sua opinião:
1- Pouco
3- Significativo
5- Altamente significativo

2- Regular

4- Muito significativo

1.4 Para você, o que é leitura?

\section{BLOCO II}

\section{LEITURA NA BIBLIOTECA}

2.1 Você vai sempre à biblioteca?

Se vai, em média quantas vezes por mês?

\subsection{Que livros você procura na biblioteca?}

Se você procura na biblioteca outros livros que gosta de ler, diga quais: 


\section{APÊNDICE B}

Questionário dos professores

Professor (a), pedimos sua colaboração no sentido de responder às perguntas abaixo. Por gentileza, responda às questões da maneira mais completa que puder. Elas comporão, com outros dados, o corpus de pesquisa de Cristina Nalon de Araujo, orientada pela profa. Dra. Lucinea Aparecida de Rezende, nos anos de 2009 e 2010, e passarão pelos trâmites de divulgação de pesquisa, preservando sua identidade.

Você tem a opção de não responder, caso entenda que não deva fazê-lo.

Em caso de dúvida, favor entrar em contato pelo e-mail crisflor_18@hotmail.com

Obrigada.

Escola:

Disciplina que leciona:

Tempo de docência:

Turma(s) para a qual leciona:

Titulação: ( ) Graduação em

( ) Especialização

( ) Mestrado

( ) Doutorado

( ) Outro. Qual?

Em relação aos alunos da $4^{\mathrm{a}}$ série do ensino fundamental:

\section{BLOCO I}

\section{ENSINO DA LEITURA}

1.1 Professor (a), como você interage com seus alunos em relação à leitura?

1.2 Quais as suas ações no ensino de leitura que a deixam satisfeita com seu próprio trabalho?

1.3 Quais as suas ações no ensino de leitura que a deixam insatisfeita com seu próprio trabalho? 


\section{BLOCO II}

\section{ALUNO E LEITURA}

2.1 Como você julga o desempenho de seus alunos em relação à leitura?

Justifique sua resposta:

2.2 Você percebe iniciativa dos seus alunos em procurar material de leitura? Como isso se manifesta?

\section{BLOCO III}

MOTIVAÇÃO

3. O que você julga necessário para motivar seus alunos para lerem mais?

Recebido em: abril de 2009

Aceito em: janeiro de 2010 